\title{
LOS TRIONFI EN ESPAÑA: \\ LA POÉTICA PETRARQUISTA, LA TEORÍa DE LA TRADUCCIÓN \\ Y LA LENGUA VERNÁCULA EN EL SIGLO XVI
}

ANNE J. CRUz

Universidad de Illinois

(Chicago. Illinois, USA)

\begin{abstract}
Se puede calcular el grado de sentido histórico yuc posec cada época al observar cómo traduce e intenta apropiarse de los tiempos y libros de antaño (F. NILTASCHI: Die fröhliche Wissenschafi)
\end{abstract}

La poesía lírica del Siglo de Oro español debe sus inicios al petrarquismo, a la imitación llevada a cabo a principios del siglo dieciséis de la poesía en italiano de Petrarca. Con la incorporación en su propia poesía de las diversas temáticas y las formas de versificación utilizadas por el poeta de Arezzo, los poetas Juan Boscán y Garcilaso de la Vega dieron ímpetu al renacimiento español, alterando significativamente el curso de la poesía española y elevando el castellano al mismo nivel cultural que el italiano. Sin embargo, mientras muchos estudios críticos se han concentrado en las imitaciones del Canzoniere, se ha prestado relativamente poca atencion a la influencia que tuvieron los Trionfi, el otro poema en lengua vernácula de Petrarca ${ }^{1}$.

\footnotetext{
'En su edición crítica de la poesía de Garcilaso, Garcilaso de la Vega: Obras completas, Madrid, Editorial Castalia, 1974, Elias L. Rivers documenta las varias imitaciones textuales del Canzoniere de Petranca. Véanse también Estudios sobre el petrarquismo en España, Madrid, Consejo Superior de Investigaciones Científicas, 1960, de Joseph G. Fucilla; Garcilaso: Esfudios completos, Madrid, Istmo, 1985, de Rafael Lapesa; y mi Imilación y transformación: El petrarquismo en la poesía de Boscán y Garcilaso, Amsterdam, Benjamins, 1988. Aparte de Francisco Rico, Bruce Wardropper ha estudiado la influencia de los Trionfi en los Triunfos

"Anurio de Esadica Mudionb", 25 (1995)
} 
Como ha verificado Ernest Hatch Wilkins, la popularidad de los Trionfi excedio considerablemente a la del Canzoniere: en el perfodo 1470-1500, se publicaron en conjunto por lo menos veinticinco ediciones del Canzoniere y los Trionfi, y nueve ediciones de los Trionfi exclusivamente ${ }^{2}$. En España, el número de traducciones y ediciones de los seis Trionfi de Petrarca da indicios, no sólo de la influencia de la poesía lírica de Petrarca, sino también de la creciente importancia, a través de las diversas prácticas de traducción, del castellano como una lengua vernácula. De hecho, las varias versiones de los Trionfi traducidas al castellano entre 1512 y 1555 nos revelan los cambios de posición con respecto a la poética petrarquista, la traducción y la lengua vernácula, al evolucionar dichas traducciones desde el estilo cancioneril medieval hasta las nuevas formas italianizantes, tomando en cuenta las conversiones a lo divino de los Trionfi elaboradas a fines del siglo dieciséis ${ }^{3}$.

Aunque en la ltalia del Quattrocento era el latín la lengua que se estimaba como el vehiculo cultural por excelencia, la creciente atención que se le fue prestando al dialecto toscano estimuló el desarrollo de la poesía lírica en la lengua vernácula. Las traducciones, no obstante, todavia continuaban real izándose, no del latín a la lengua vernácula, sino justamente a la inversa. Según William Melczer, la lengua vernácula no comenzó a asumir cierto grado de importancia sino hasta principios del Cinquecento, debido en gran parte al interés que despertaron los tratados neoplatónicos sobre el amor y la belleza, los cuales terminaron por inclinar la balanza a favor del italiano ${ }^{4}$. De ahr que el neoplatonismo asegurara la igualdad espiritual de todos los idiomas ya que se consideraban como manifestaciones del alma humana, e igualmente dignos de servir de comunicación con la divinidad (MELCZER 262).

morales (1587) de Francisco de Guzmán; en los Triunfos del amor (1598) de Juan de los Angeles y en los "Triunfos divinos" de Lope de Vega. Alicia de Colombi-Monguió señala la imilación de los Trionfi por Dávalos en eu estudio, Petrarquisıno penuano: Diego Dávalos y la "Miscelánea Austral", London, Tamesis, 1985, pp. 196-204.

${ }^{2}$ Emest Hatch WILKINS, The Making of the Canzoniere and Other Petrarchan Studies, Roma, Edizioni di Storia e Letteratura, 1951, pp. 196-204.

${ }^{3}$ Bruce W. WARDROPPER, Historia de la poesía lírica a lo divino en la cristiandad occidental, Madrid, Revista de Occidente, 1958, pp. 272-275.

- William MELCZER, Towards the Dignification of the Vulgar Tongues: Humanistic Translations into Italian and Spanish in the Renaissance, "Canadian Review of Comparative Literature", 2 (1981), 258 ff. Las traducciones de las citas al castellano son mias. 
Aparte de su impacto en la difusión del humanismo europeo, las lenguas vernáculas contribuyeron al desarrollo de una conciencia nacional, como ha estipulado Ian Parker:

La imporancia de la literatura en lengua vemácula en parte consiste en el reflejo y desarrollo de una concientización "nacional", de un sentido de la historia y de orgullo propios ... y en parte en la exploración y delineación de la experiencia individualizada de dicha concientización. . Pero tamhién resultó scr importante en cuanto indicaba y extendía la capacidad expresiva de las lenguas vemáculas, o fomulaba una conciencia de y un orgullo en las propias lenguas'.

La publicación a fines del Quattrocento de las obras en lengua vernácula del triunvirato literario de Dante, Petrarca y Boccaccio, seguida en el Cinquecento por su valorización en los tratados bembianos Prose della volgar lingua y De imitatione, en los cuales el cardenal enfatiza la imitación ciceroniana, aseguraron tanto el continuo desarrollo de la lengua como la constante difusión del pensamiento humanista italiano.

Es por ello que la traducción se mantiene intimamente ligada a las fuerzas polfticas e históricas as como a la teoría poética. Efectivamente, toda composición poética representaba un acto polftico, puesto que el concepto de imitación en que se basaba implicaba una estricta adherencia a un solo modelo clásico, o al contrario, una imitación ecléctica de varios modelos por modio de la cual se admitfan las diferencias existentes entre culturas. El crítico norteamericano Thomas $M$. Greene aserta que los ciceronianos, con Bembo al frente, promulgaban la contigüidad de sus imitaciones con su glorioso pasado latino, mientras que los anti-ciceronianos reconocian y aceptaban la discontinuidad histórica entre la imitación y su modelo ${ }^{6}$. No deja de ser irónico, por tanto, que el pensamiento progresista que manifiesta Bembo en cuanto a la importancia de la lengua vernácula queda subvertida al insistir de forma dogmática en la imitación ciceroniana. El clasicismo predomina en la literatura italiana desde aproximadamente 1494 hasta 1559, perfodo que coincide con la invasión extranjera, y no es accidental que el formalismo bembiano corresponda a la negación en la que insiste el teórico

\footnotetext{
STan PARKER, The Rise of the Vemaculars in Early Modem Europe: An Essay in the Political Economy of Language, en The Sociogenesis of Language and Human Conduct, ed. Bruce Bain, New York, Plenum Press, 1983, p. 340.

Thomas M. GREENE, The Light in Troy: Imilation and Discoveny in Renaissance Literature, New Haven, Yale University Press, 1982, pp. 173-176.
} 
de la nueva hegemonfa política española que efectivamente desplazó a la nacional (GREENE, 175).

Concentrándose más bien en su literatura vernácula, los italianos continuaron la traducción de los clásicos latinos, dominando el campo de la teoría poética hasta fines del siglo dieciséis. El aumento que se nota en las traducciones de otras literaturas al italiano, sin embargo, marca el paulatino debilitamiento de la influencia literaria italiana, al llegar a asumir las demás lenguas vernáculas la misma importancia que el italiano habra gozado previamente. Asf, Carlo Dionisotti considera que la traducción hecha por Castelvetro de un poema de Ronsard en 1559 inicia el final de la influencia literaria italiana, y la traducción de los Essais de Montaigne en 1590 marca el momento decisivo cuando se pierde del todo?.

Aunque el humanismo español dependra sustancialmente del pensamiento humanista italiano, la devaluación política de Italia coincide con el desarrollo del castellano en su capacidad de lengua nacional. Aún antes del oportuno comentario nebricense de "la lengua del imperio" que prologa su Gramática, el traductor Gonzalo Garcia de Santa María ya habra propuesto en 1490 su razón para efectuar el cambio del latín al castellano, insistiendo en que la lengua vernácula castellana contribuiría a la unidad política que se deseaba realizar bajo las coronas recién unidas de Castilla y Aragón. ${ }^{8}$. En la esfera literaria, el hecho de que los mismos poetas italianos que practicaban la traducción eran imitados por sus contemporáneos españoles no sólo estimulo la versificación italianizante en España, sino que también dió impetu al acto mismo de traducir. Junto con la imitación, pues, la traducción en España llegó a jugar un papel significativo en la expansión de la lengua vernácula; razón por la que no se debe separar del adelanto de la poética española renacentista ni tampoco de su subestrato ideológico, pues ofrece una manera de medir y evaluar la expansión del poder político español en la Europa renacentista.

Con todo, la versificación italianizante no llego a eclipsar enteramente la poeśa cancioneril tradicional tan de moda en el Medievo. La primera

\footnotetext{
'Carlo Dionisotn, Europe in Sixteenth-Century Italian Literature, Oxford, Clarendon Press, 1971, pp. 17-19.

"Eugenio Asensio ha afirmado que García de Santa Maria "en el prólogo a su traducción de las Vilae Palrum, Zaragoza, circa 1490, proclamó la necesidad de que el nuevo imperio de los Reyes Católicos adoptase el castellano como instrumento de la unidad política: con ello se adelantó al memorable prólogo de Nebrija a su Gramática Castellana"; citado en Domingo YNDURAIN, La invención de una lengua clásica" en "Edad de Oro", 1 (1982), pp. 13-34.
} 
traducción en castellano de los Trionfi de Antonio de Obregón se publicó en 1512, unos doce años antes de que Boscán intentara imitar los versos italianos. Tanto Obregón como el poeta cancioneril Alvar Gómez de Ciudad Real compusieron sus versiones siguiendo el estilo del cancionero medieval, cuyas características principales incluyen la amplificatio, la paronomasia, y los juegos de conceptos en versos octosilábicos ${ }^{9}$. Aunque Obregón no ha sido tomado en cuenta por la mayoría de los bibliógrafos, debemos reconocer que su traducción es la primera versión completa de los Trionfi en castellano -una traducción cuya popularidad fue atestiguada por al menos cuatro ediciones publicadas entre 1512 y $1541^{10}$.

En efecto, la temprana fecha de la traducción de Obregón nos confirma que el ambiente cultural y político en la España precedente a la llegada de Carlos I ya se mostraba lo suficientemente receptivo a los cambios que efectuarían una década más tarde Boscán y Garcilaso de la Vega. El estilo cancioneril, por lo tanto, en ningún momento obvia la fase tan significativa que llego a representar la traducción en el desarrollo de la poética española renacentista. Según Giovanni Caravaggi,

l'allargamento rapido e smisurato dei confini politici e dell'area d'influenza della Spagna comporti la rottura degli stessi limiti culturali; il contatto o lo scontro con altre

\footnotetext{
'Rafael LAPESA, Poesta de cancionero y poesta ilalianizante, en De la Edad Media a nuestros dias: Estudios de historia literaria, Madrid, Editorial Gredos, 1967, pp. 145-171.

${ }^{10}$ La Biblioteca Nacional en Madrid contiene las siguientes ediciones de las traducciones de Obregón: R-8092 (Logroño 1512); R-11730 (Sevilla 1526); R-92 (Sevilla 1532); R-12172 (Valladolid 1541). Ademas de las tres traducciones que mencionamos en este estudio (Obregón, Gómez, y Hozes), también existen las traducciones sin publicar de Luis Zapata, Jerónimo de Urrea (1549), y Alcocer (1550) que conocia Hemando de Hozes (véase Francisco RICO, El destierro del verso agudo, "Homenaje a José Manuel Blecua ofrecido por sus discípulos, colegas y amigos", Madrid, Editorial Gredos, 1983, p. 533, n. 31); y el Triunfo de la muerte de Juan de Coloma, en estilo cancioneril, incluido en el Cancionero general de obras nuevas, en L'Espagne an XVIe et XVIIe siècle, ed. A. MOREL-FATIO, Hcilbronn, 1878. He encontrado pocas referencias a Obregón en las fuentes bibliográficas tradicionales. Nicolás Antonio cataloga a Obregón como "Antonius de Obregon et Zerezeda, canonicus Ecclesiae Legionensis Philippo II", y le atribuye erradamente Los triunfos del Petrarca en la medida y número y versos que tienen en el loscano, con su glosa, de Hernando de HozES (Salmanticae, 1581); véase m Bibliotheca Hispana Nova, presentazione di Mario Ruffini, Torino, Bottega d'Erasmo, 1963, p. 147. Tampoco se incluye a Obregón en el Ensayo de una bibliotheca de traductores espatoles, Madrid, 1778, de Juan Antonio Pellicer y Saforcada ni en la Biblioteca de iraductores espanoles, de Marcelino Menéndez y Pelayo (vols. 54-57, Edición Nacional de las Obras Complesas de Menéndez Pelayo, Madrid, Consejo Superior de Investigaciones Científicas, 1952), por lo que podemos asumir que sus treducciones no incluian textos biblicos ni clásicos. B.J. Gallardo apene le dedica una nota sobre una de sus traducciones tardias en su Ensayo de una biblioteca espatola de libros raros y curiosos, Madrid, Editorial Gredos, 1968, vol. 3, p. 1003.
} 
civilta. mentre impone un confronto ideologico ximolante, facilith la tramissione di mode earnece, acceltnte speseo in modo disordinelo, ma sempre con una carica di entusinemo capace di roveaciare le tredizioni piu alde".

Vemos, pues, que aún cuando se efectúa en estilo cancioneril, la traducción de Obregón participa de lleno en la revolución literaria que en España surge a través de la difusión de textos, de las nuevas corrientes humanisticas y, sobre todo, del contacto y enfrentamiento con la lengua y la cultura italianas.

Por otra parte, las traducciones de los Trionfi en diferentes estructuras sintácticas y morfológicas ejemplifican las dificultades por las que tiene que pasar en el renaciniento todo traductor de lengua vernácula ${ }^{12}$. Las teorías humanisticas sobre la traducción cubrfan toda una gama de tendencias contrastantes; por un extremo, el acto de traducir se percibla como una transferencia estática semántica, y por el otro, como una transformación dinámica de elocución. Como afirma Glyn P. Norton en su estudio de la práctica renacentista de la traducción, la densidad de la palabra asegura su autonomia, pero también implica un desequilibrio cuantitativo entre el original y su traduccion: "Toda buena traducción es más extensa que el texto original y en su traslado a la lengua propuesta, las palabras del texto de procedencia padecen un acrecentamiento de substancia" ${ }^{13}$. Las traducciones filologicas fueron motivadas por un doble deseo, el de rendirle homenaje al texto original por medio de su revitalización, y el dar cuenta de ciertas estructuras a través de su transformación:

La fe humaniatica en un mundo tranecendental de valores esenciales mantenida por una estructura hermética lingüistica enriquece . . . la traducción filológica en un procedimiento doble: por un lado, el escrutinio de unidades léxicas yuxtapuestas; por

\footnotetext{
"Giovanni Caravaggi, Alle origini del petrarchismo in Spagna, "Miscellanea di Studi Ispanici", Pisa, latituto di Lingua e Letteratura Spagnola, 1971, p. 8.

${ }^{12}$ Aunque la literatura sobre las traducciones renacentistas es extensa, hay pocos estudios sobre la traducción al español exclusivamente. Hago constar mis agradecimientos a Brian Striar por en referencia a los estudios de Glyn P. Norton. Para otros estudios sobre la traducción, véase STRUR, Theories and Practices of Renaissance Verse Translation, Disa., Claremont Graduate School, 1983; Gianfranco FOLENA, Volgarizzare e tradurre, en La tradwzione: saggi e studi, Triente, 1974, pp. 59-120; Eugenio CosERr, Tradición y novedad en la ciencia del lenguaje, Madrid, Gredos, 1977; y Valentín GARCLA YEBRA, En tomo a la traducción: Teorlas, crifica, historia, Medrid, Grodos, 1983.

${ }^{13}$ Glyn P. NORTON, Humarist Foundarions of Translation Theory (1400-1450): A Study in the Dynamics of the Word, "Canadian Review of Comparative Literature", 2 (1981), p. 176.
} 
el olro, la recuperación y recreación del significado. El primer procedimiento alaca la opacidad de las palabras individuales, en cierre y resistencia; el segundo, la fucris enérgica de la elocución, las complejas fuerzas de an enunciación y revelación (NORTON, 1981, 178).

Es en el intento de establecer un equilibrio entre fidelidad y libertad en el acto de traducir, esquivando los extremos, que se llega a lo esencial de la traducción retórica, sustentada como está por el redescubrimiento de los principios pedagógicos clásicos. No obstante, dicho intento también nos revela las tensiones existentes entre dos sistemas poéticos que compiten entre si, asl como de la especificad histórica de toda tradución.

El primer tratado renacentista sobre la traducción. De interpretatione recta, escrito en 1426 por el erudito y traductor italiano Leonardo Bruni, articula una toorfa de traducción hasada en una retórica de intrusión y dinamismo. Según Bruni, la traducición radica en la conversión del texto por medio del entendimiento, de la mente, y de la voluntad, y a su vez la transformación del estilo para asf lograr expresar todas las características del original (NorTON, 1981, 189-90). El tratado de Giannozzo Manetti también titulado De interpretatione recta (1455-59) se limita más en su definición de lo que es para él la traducción correcta. El tratado sintetiza el pensamiento de Bruni de que las palabras son depossitos de energf́a latente que el traductor suministra al nuevo texto, ya sea ad verbum, enfatizando la réplica literal; ad sensum, observando sólo el sentido y eliminando todo adorno figurativo; o en un tercer modo, agregando o eliminando palabras sólo con el propósito de adornar (NORTON, 1981, 198-99). Al rechazar la división entre res y verba, el acercamiento relativista de Manetti entiende la traducción como una red de estrategias entre palabra y esencia, que incorpora simultáneamente tanto las energías afectivas como las significativas del lenguaje.

Aunque el Comento de Eusebio de Alfonso Madrigal el Tostado es la única obra española del quinientos sobre la traducción que tuvo una amplia divulgación en el siglo dieciséis, refleja las mismas cuestiones que vemos indagadas por los tratados italianos anteriores. Para llegar a la más cercana aproximación del estilo y significado del texto original, Madrigal recomienda que se efectúe una traducción de "palabra a palabra", estrategia que él llama "interpretación" o el acrecimiento de palabras que intentan "explicar" el texto original, que él llama "glosa": 
Dus sun las inarkiras de trasladar: vna ca de palabre a palabra, a llemase inteprelacicin, otra ca ponicndo la mentencia sin ucguir las palabras. la qual ec faze comunmente pur inas lucngas pulabras a can se llame exposicion o comento o glosa. La primera es de mas auloridad, la scgunda es mas clara pare los menores ingenios. En la primera mon se ariade, a porende siempre es de aquel que la primero fabrico. En la segunda sc farcn muchas adicioncs a mudamientos, por lo qual non es obra del autor, mas del glosador'te.

Por lo visto, Madrigal asigna a la "interpretación" la representación del texto (original, mientras que la "glosa" asume una función menos importante. Sin emhargo, en su propia traducción del In Eusebium comisionado por el marqués de Santillana, El Tostado se da cuenta que la "interpretación" requiere una "glosa", y aunque se refiere a ella como a "breues declarationes," el Comento luego se convirtió en obra de cinco tomos:

Emperm por que cyla translation, fecha de palabra en palabra, en algunos logares seria muy cacura, quisc faycr algunas hreucs declarationcs, las quales fuessen en manera de postillas sobre algunas partes del ICMO (citado en KIJGHTIEY, 244-245).

La perspectiva de Madrigal sobre la traducción se acerca notablemente a la que postulara un siglo después fray Luis de León, como Manetti hebraista y traductor de la Biblia, y sin duda influenciado por el traductor italiano. En su traducción del Cantar de los cantares, sin embargo, fray Luis difiere de Madrigal en que no concuerda con el poco valor que éste le asigna a la glosa:

Lo que yo hago en esto son dos cosas; la una es volver en nuestra lengua palabra por palabra el texto de este Libro; en la segunda, declaro con brevedad no cada palabra por sí, sino los pasos donde se ofrece alguna obscuridad en la letra...poniendo al principio el capítulo todo entero y después de él su declaración ${ }^{15}$.

Según los humanistas renacentistas, pues, la traducción debe procurar preservar el texto original mientras ofrece una nueva versión, basada no en una verdad esencial, sino en cambios semánticos y desplazamientos condicionados históricamente.

${ }^{14}$ Citado en R.I. KegGhtuey, Alonso de Madrigal and the Chronici Canones of Eusebius, "The Joumal of Medieval and Renaissance Studies", 7 (1977), p. 246.

${ }^{15}$ LUIS DE LEÓN, Obras completas castellanas, Madrid, Biblioteca de Autores Cristianos, 1959, p. 65. 
La traducción de Obregón de los Trionfi sigue la edición anotada de 1475 por Bernardo da Pietro Lapino da Montalcino (conocido también como Bernardo Glicino o Illicino), que incluye un extenso comentario de unas quince a veinte palabras de exégesis por cada palabra del texto original $\mathbf{v}$ que influyó a todos los comentaristas subsiguientes del texto ${ }^{16}$. La dedicatoria a Fadrique Enriquez de Cabrera, Almirante de Castilla, muestra claramente que Obregón conocia la distinción hecha por Madrigal entre "interpretacion" y "glosa":

\footnotetext{
y procure yr tan cerca del original en todo que por maravilla se hallara verso mio en castellano que no vaya declarado lo que mi poeta diac por sus vocahlos toscanos porque me parescio justa cosa ser yo interprete tan fiel que no me yuedasse osadia de quitar ni poner en obra lan distilada y excelente de cuya causa iuve por bien defforzarme a no trovar tan galan ell castellano como se podicra haver si me quisicra apartar tomando alguna licencia delo toscano".
}

Con todo, si comparamos la traducción de Obregón con el texto original notamos que si ha tomado licencia considerable. Su versión en estilo cancioneril da amplias muestras de las dificultades que existen en traducir de una forma poética a otra, ya que el esquema en terza rima de los endecasnabos originales debe cambiarse a quintillas dobles octosilábicas, cambio que extiende la longitud del texto original italiano: mientras los cuatro capitoli del Triumphus Cupidinis únicamente miden 700 versos en hendecasnabos, el texto de Obregón, de 1,290 versos octosilábicos, casi dobla el largo del poema original. Tampoco es ésta la única disparidad entre los textos, a pesar de insistir Obregón en que ha permanecido fiel al original. El Triumphus Cupidinis de Petrarch comienza:

\author{
Al tempo che rinnova i miei sospiri \\ per la dolce memoria de quel giomo \\ che fu principio a si lunghi martiri, \\ gia il Sole al Toro l'uno e l'altro como \\ scaldava, e la fanciulla di Titone \\ correa gelata al suo usato soggiomo. \\ Amor, gli sdegni e "I pianto e la stagione
}

\footnotetext{
' ${ }^{16}$ D.D. CARNICEU, Lord Morley's 'Tryumphes of Fraunces Petrarcke': The First English Translation of the "Trionfi", Cambridge, Harvard University Press, 1971, p. 29.

"Francesco PETraRca, Francisco Petrarca con los seys triunfos de toscano sacados en castellano con el comento que sobre ellos se hizo, Logroño, 1512, fol. ij.
} 
ricondoto $m$ 'aveano al chiuso loco ov' ogni faccio il cor laneo ripone.

Ivi fra l'erte, gin del pianger froco, vinto dal eonno, vidi una gran luce e dentro aseai dolor con breve gioco.

Vidi un vittorioes e commo duce pur com'un di color che 'n Cempidoglio trionfal carro a gran gloria conduce.

l'che gioir di tal vista non eoglio per lo secol noioso in ch'i'mi trovo, voto d'ogni valor pien d'ogni orgoglio, mirai".

l'abito in vista si leggiadro e novo

Estos diecinueve versos se expanden en la traducción castellana de Obregon a las siguientes seis quintillas dobles:

En el tiempo que muy nueva

estava la pena mia por memoria que renueva el mal que supe por prueva en el semejante dia del tauro el sol calentava el uno y el otro cuemo. El alva ec levantava y corricndo caminava con cl rostro cludo y ticmo.

El amor y desdcñar con el ticinpo y con el llanto me cerraron en lugar donde suele descansar el coraçon de quebranto. Cansado de llorer canto entre las yerbas dormido vi gran luz donde ove espanto y yo vi dentro entre tanto breve rise y gran gemido.

Vi que con mucha victoria

un gran capitán venia como aquel que por memoria

"Francesco PETRARCA, Triumphus Cupidinis 1.1-20, en Rime, Trionfi, e Poesie Latine. A cura di F. NERI, et al., Milano, Riccardo Ricciardi Editore, 1951. 


\begin{abstract}
al capitolio con gloria
triumphal carro conduzia

Yo que gozar no solia

en tal edad tal plazer

por ser de virtud vazia

y llena de fantasia

alze los ojos por ver.."
\end{abstract}

Notamos que asf como Obregón no sigue fielmente el sentido del texto original, tampoco se acerca mucho el vocabulario que escoge para reemplazar el italiano. Las tensiones entre los dos sistemas se echan de ver en la traducción que intenta de la viva descripción que hace Petrarca del alba, "e la fanciulla di Titone / correa gelata al suo usato soggiorno". Aparte de su obvia perffrasis de la Aurora, la figura mitológica evocia la imagen distante de Laura, la amada de Petrarca, yuien huye por los cielos, ya que el tempo al que alude el poema es el 6 de abril, la fecha funesta del primer encuentro del poeta con Laura y de la muerte de ésta. Al reducir la figura mitológica a su acepción temporal univalente de la madrugada, la versión castellana de "alva" efectivamente pierde la fuerza evocadora del mito clásico y del poema petrarquesco, cuyos versos nos permiten vislumbrar a una joven quien, al despertar, echa a correr a paso rápido, su cara tierna y fría por el aire helado de la mañana.

La tercera quintilla doble también carece de la calidad alusiva de las referencias petrarquistas. En el original, Petrarca declara que una combinación de sus emociones, el rechazo de Laura, y el hecho de que era la estación de primavera, lo habia llevado al chiuso loco -Valchiusa como un locus amoenus- donde, al revivir sus memorias, él podría paradojicamente aliviar su corazón. Obregón interpreta la situación del poeta en un sentido mucho más estrecho como si estuviera enclaustrado por el amor y el desdén de su amada en un lugar, no especificico, donde sólo le es permitido descansar. Por más que procure evitar toda traducción ad verbum, como advertía Horacio en su mandato, "nec verbo verbum curabis reddere fidus / interpres ${ }^{200 ",}$ vemos que Obregón no puede aprovecharse por completo de la alusiva

\footnotetext{
${ }^{19}$ Petrarca (1512) fols. VI-VII

${ }^{20}$ Glyn P. NORTON, The Ideology and Language of Translation in Renaissance France and their Historical Antecedents, Geneva, Droz, 1984, pp. 57 ff. Véase también André LEFEVERE, Translating Literature: The German Tradition froin Luther to Rosenzweig, Assen, Van Gorcum, 1977, pp. 24-25.
} 
terminologfa petrarquista, y se ve forzado a escoger sólo una de sus muchas posibles acepciones ${ }^{21}$.

Aunque Obregón queda atrapade en las redes culturales de un sistema poético diferente que no le permite la flexibilidad de transferir el significado de una palabra a otra, es obvio que tampoco ha traducido el poema enteramente ad sensum. Las diferencias en significados deben tenerse en cuenta como una manifestación de las ideologfas poéticas opuestas entre el estilo cancioneril y la lfrica amorosa petrarquista. Las variaciones semánticas derivan del gusto cancioneril por lo) abstracto, que choca con el lenguaje poético codificado de los Trionfi y el Canzoniere. Quedan eliminados los términos afectivos petrarquistas tales como lunghi y dolci, y los términos concretos italianos, sospiri y martiri, son reemplazados por las libres abstracciones castellanas de "pena" y "mal". No obstante, las diferencias que resultan de estos dos sistemas no contradicen el axioma humanista de que todo texto literario imita la vida humana, y que dichos textos "se mantienen por una aglomeración de estructuras que responden a las texturas variables y cambiantes de la experiencia humana" (NORTON 1984, 54). Cada sistema poético refleja su posición histórica particular, asf como expresa su propia aproximación a la representación de las emociones humanas.

La segunda traducción de los Trionfi publicada en España fue la versión de Alvar Gómez del Trionfo d'amore ${ }^{22}$. Aunque también se tradujo en estilo cancioneril, difiere del texto original y de la versión previa de Obregón, como podemos ver en sus primeras seis quintillas dobles:

Al ticmpo qu'en mi porfia

\footnotetext{
${ }^{21}$ Para una discusión que scñala las muchas dificultades en traducir el lenguaje poético petrarquista, véase el prólogo de Robert Durling de su traducción en prosa del Canzoniere, Petrarch's Lyric Poems: The 'Rime Sparse' and Other Lyrics, Cambridge, Harvard University Press, 1976, pp. VII-XII.

${ }^{2}$ La traducción de Gómez se incluyó en el Cancionero de Juan Femández de lxar, ed. José María AZACETA, Madrid, Consejo Superior de Investigaciones Cientificas, 1956, vol. 2, pp. 819-862; y con variantes, en el Cancionero de Gallardo, ed. José María AZÁCETA, Madrid, Consejo Superior de Investigaciones Científicas, 1962, pp. 98-151. Aunque las traducciones de Gómez no han sido fechadas, scgún Azáceta, el traductor murió en 1538, así que no hubiera conocido la versión de Hozes (Cancionero de lxar l. XCVI). Según Azáceta, la traducción de Gómez fue tan popular que se incluyó en las siguientes ediciones de Los siele libros de la Diana de Jorge de MONTEMAYOR, Cuenca 1561; Valladolid 1561; Alcalá 1564; Lisboa 1565; Pamplona 1578; Venecia 1585; Madrid 1586; Madrid 1595; Valencia 1600; Madrid 1602; Lisboa 1624. Sin embargo, Azáceta señala que el texto en estas ediciones ha sido substancialmente reducido a ochenta y ocho versos (Cancionero de Ixar I. XCVIII).
} 


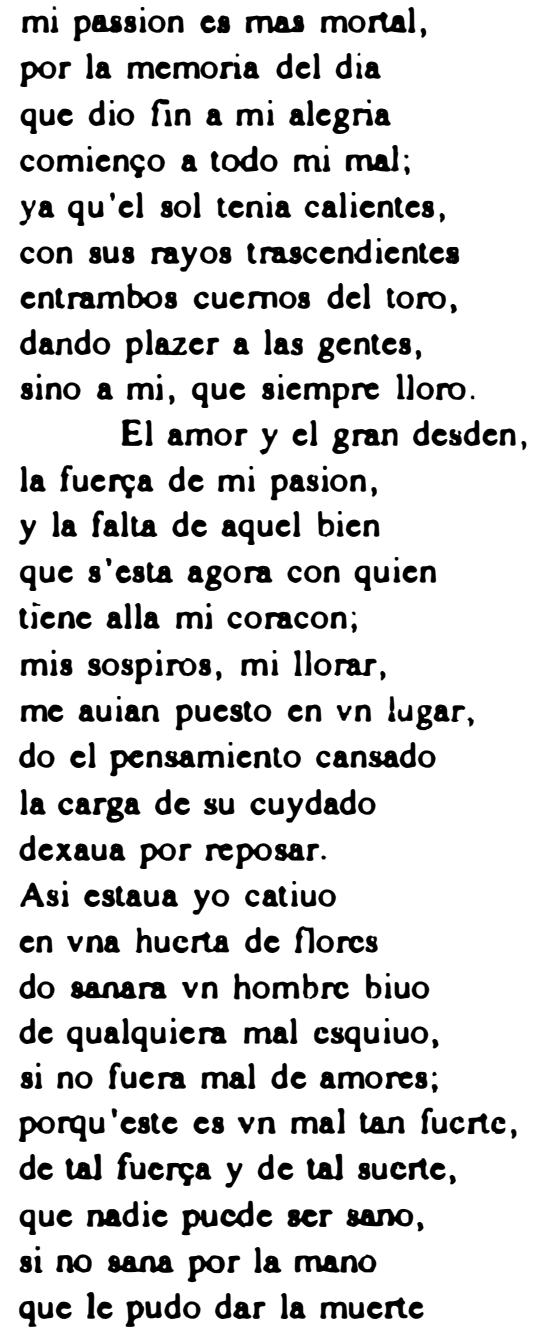

Como Gómez rechaza una aproximación verso por verso del texto original, su traducción es aún más extensa que la de Obregón: desde los 700 versos endecasilábicos del original se alargan a 1,430 versos octosilábicos. Aún as!, las primeras seis quintillas dobles no llegan a mencionar el profundo sueño en que cae el amante, sueño que califica al poema de visión onirica y que prepara al lector para el tercer Trionfo sobre la muerte. Al contrario, las razones del poeta por su estado emocional mientras descansa paradojicamente en un locus amoenus ("huerta de flores") se ampl fan repetitivamente en la traducción, incluyendo no soblo el amor del poeta, el gran desdén de la amada, la fuerza pasional de aquél y la ausencia de ésta, sino también los suspiros y lamentos del poeta. Los últimos cinco versos de la sexta quintilla incluyen una típica paronomasia cancioneril, "fuera /fuerca / 
fuerte", además del juego de vocablos opuestos de "mal / sano". El último verso también introduce el factor causal ausente en el poema de Petrarca: el mal de amores es tan abrumante que sólo puede curarse el amante por la única mano capaz de matarlo ${ }^{2}$.

Francisco Rico ha estudiado las dificultades que se presentan al tratar de traducir los topoi petrarcanos en el esquema poético cancioneril español ${ }^{24}$. Encuentra que la quintilla doble 78 de la traducción de Gómez varía mucho de su fuente petrarcana, "so come sta tra' fiori ascoso l'angue.../ e so in qual guisa / l'amante ne l'amato si trasforme" (PeTrarca, Triumphus Cupidinis III. 157, 161-162):

Se como esta entre la rosa

metida la crueldad;

y mi pera dolorose

se ser vna misma cose

con su mesma boluntad;

no porque yo diga d'clla

que boluntad ay en ella

de aquello que quicro yo,

mas lo que clla quicre so,

sin pensar en no querella

(Cancionero de Gallardo, 127).

La tesis central de Rico es que el petrarquismo en realidad está presente en el cancionero, aunque sus conceptos se manifiestan a través de un sistema poético diferente ("por via de intelectualización y no de imaginerfa"), y la alusividad del original queda reducido a la univocalidad del estilo cancioneril (RICo, 1978, 330). Lo que nos interesa aqul, sin embargo, son los cambios que ocurren en el sentido de la traducción. Como confirma Aldo Bernardo, los últimos versos del Triumphus Cupidinis se desplazan al pasado, revelando que el sueño del poeta ocurre con anterioridad a su encuentro con Laura el 6 de abril ${ }^{2 s}$ :

\footnotetext{
${ }^{23}$ La inclusión en la traducción en castellano del tema del mal de amor, explicitado en el Canzoniere pero no mencionado en los Trionfi originales, apoya la opinión de Sare SturmMaddox de que los Trionfi dependen mucho mas del Canzoniere, tanto intertextual como subtextualmente, de lo que han notedo los críticos.

${ }^{24}$ Francisco RICO, De Garcilaso y otros petrarquismos, "Révue de Littérature Comparee" 52 (1978), 325-338.

${ }^{25}$ Aldo S. BERNARDO, Petrarch, Laura and the 'Triumphs', Albany State Univeraity of New York Press, 1974, p. 103.
} 
Rimirando er'io falto al sol di neve

tanti spini e si chiari in carecr tctro.

quasi lunga pillura in tempo hreve.

che'l pic va innarui c l'ocichio loma a dictro

(Triumphus Cupidinis IV. 163-66)

Los versos del Trionfo d'amore, impregnados de tristeza y phenos de nostalgia por un pasado que no ha ocurrido aún, reiteran el tono del Canzoniere de un amante prisionero de amor y anticipan el segundo Trionfo sobre la castidad. en el que Petrarca celebrará en cambio su resistencia a Laura (Bernardo, 115-116). En contraste. Gómez termina su lamento con una nota victoriosa, orgulloso de que su amor excede en todo a los demás:

Ansi que digno herdan.

que inucho licmpo esto yo)

con alegre holuntad

sin sentir la enceldad

de las penas en yuc esto

Asi los conamorados

que inis palahras oystes.

consuclen vucstros cuydados.

quando mas descsperados

la causa porque os perdistes:

que aunque van mis hozes Iristes

con la pena que me histes.

alegre esta el coraçon

en berse con mas pasion

que nunca todos tuuistes

(Cancionero de liar. II.1411-30)

Al no seguir el sentido del texto de Petrarca, tanto Obregón como Gomez lo subvierten para interpolar en cambio su propia retórica poética. Por ende, las traducciones se separan del texto original, pero su existencia en si afirma lo que Walter Benjamin llama la "vida futura" (afterlife) del original o sea, que la traducción ha resultado ser una transformación y renovación del original ${ }^{26}$. Las diferentes traducciones de los Trionfi no solamente le

${ }^{26}$ Walter BENJAMaN, The Task of the Translator, en Illuminations, ed. Hannah ARENDT, New York, Schocken Books, 1969), p. 73. 
aseguran a los poemas petrarcanos una vida perdurable, sino que demuestran los cambios que sufre toda lengua y, por consiguiente, toda traducción. Al aducir la historicidad de los textos traducidos, aserta Benjamin que "mientras los vocahlos de un poeta perduran en su propia lengua, hasta las traducción más memorable está destinada a formar parte del desarrollo de su propia lengua y a ser ahsorhida eventualmente por su renovación" (BENJAMIN 73).

A pesar de la popularidad de la traducción de Gómez a través del siglo diecisćis, la aparicioín en 1554 Je una versión italianizante de los Trionfi por Hernando de Hozes subraya la necesidad, no sólo de renovar el poema original, sino también de crear una nueva versión en castellano basada en la poética del lenguaje y versificación petrarcanos. Los primeros veintiún versos del Triunfo del amor Jemuestran cómo Hozes ha imitado los capitoli en terza rima de Petrarca:

Al licinpo que renueva cl mal que siento por la dulce memoria de aquel dia, en quien principies luves ini lonnentos:

el Sel coll ranbess cucmos ya encendia del Tors, y el Aursora muy screna y helada va corricindo a do solia Ainor, desdencs, llanto, el licinpo y pena inc hahian pucstos en el lugar cerrados adonde loda cuila queda ajena.

Entre las ycrtias de llorar cansado durmiendo vi una luz resplandeciente y dentro placer breve y gran cuidado.

Vi un victorioso capilán valiente como los que en el carro triunfunte al Capitolio fucron con su gente.

Yo, que gozar de vista scmejante no suclo en cste siglo trabajoso, sin bicn y de congojas abunduntc, cl hábito no usado y tan poinposo mirć, los nacos ojos levantando, que solo el aprender me da reposo 27.

\footnotetext{
${ }^{27}$ Francesco PETRARCA, Trivmphos de Francisco Petrarca ahora neuvainente traduzidos a lengua Castellana en la medida, y numero de versos, que tienen en el toscano y nueva glosa, Medina del Campo 1555, fol. VIill.
} 
En 1550, Hozes decide pulir la traducción que habra hecho de los Trionfi en 1549 con el intento de eliminar los versos finales oxftonos y aproximarlos más al esquema de la rima italiana (Rico, 1983, 525-51). En el prólogo de su edición de 1555, advierte al lector las diferencias entre su versión y el modelo italiano:

También quiero preunir al lector, que hallara encsta traduction algunas cossas quitadas, y muchas de otra manera pucstas de como estan enlo Thoscano. $Y$ no cinhargante que la mayor parte dela culpa desto sea el mal entendimiento del traductur que no accro a darle mejor traca: tambien para lo que se quito fue mucha ocasm,n ser lus vocablos dela lengua Thoscana por la mayor parte de menos syllahas que los que quicren decir lo mismo en la castellane y desta causa de necesidad se ouicron de quitar algunas palabras, porque a no hazerse, o tenia de lleuar mas versos de los yue ticne cl Thoscano, o lo que lleuaria yr mas largos jelo que la medida dellos requena ${ }^{2 n}$.

Hozes declara tener otro propósito en traducir los Trionfi que el de imitar únicamente del italiano; desea además recordar los muchos poemas valiosos escritos en estilo cancioneril, entre los cuales incluye la traducción previa de los Trionfi por Obregón:

Despues que Garcilasso de la Vega y Juan Boscan truxcron a nuestra lengua la incdida del verso Thoscano, han perdido con muchos tanto crédito todas las cosas hechas, o traduzidas en qualquier género de verso de los que antes en España se vsauan, que ya casi ninguno las quicre ver, siendo algunas (como cs notorio) de mucho precio. $Y$ como vna dellas, y aun a mi paresecr de las mejores, fucsse la traduction de los Triumphos de Petrarcha, hecha por Antonio de Obregon, poryuc algunos amigos mios que no entendian el Thoscano, no dexassen por esta causa delver vna cosa de tanto valor como los dichos Triumphos son, en algunos ratos de verano passado, que para ello tuue desoccupados, hize otra nucva traduction en la misma medida y numero de versos que el Thoscano tiene (Trimphos, 1555,I).

Su nueva traducción, que cuenta con el mismo número de versos que el original, también modifica la glosa que acompañaba el poema y que Obregón habla traducido de Illicino:

Y así mismo le puse nuevo commento, no tan breue como el de Alexandro Vellutcllo, ni tan largo en muches coses, como el de Bemardo Illicinio, sino tomando a pedaços

\footnotetext{
${ }^{23}$ Francesco PETRARCA, Trivmphos de Francisco Petrarca ahora nuevamente traduzidos a lengua Castellana en la medida, y numero de versos, que tienen en el toscano y nueva glosa. Medina del Campo 1555, fol. I.
} 
de entramibos, quilando algo de lo que pareacia superfluo y eriadiendo lo que en mi juizio era muy noceanvio (Trimphos, 1555, I).

Sin embargo, a pesar de los esfuerzos del autor por revivir el interés en la traducción cancioneril anterior, la versión italianizante de Hozes, con su nueva glosa sintetizada, termina por suplantar la de Obregón. Según Rico, esta versión representa una de las mejores traducciones del italiano en castellano, al superar Hozes admirablemente las dificultades planteadas por la rima oxitónica castellana. Rico ha comparado el rechazo de Hozes del verso oxitónico por el verso paroxitónico con la sustitución de la questio escolástica medieval por los géneros humanísticos renacentistas tales como el ensayo y el diálogo, puesto que su exposición en lengua vernácula permitfa una difusión más extensa, de manera semejante a la mayor atención que recibe la nueva versión italianizante en comparación con el viejo estilo cancioneril (Rıco, 1983, 549). El hecho de que Hozes eliminara los versos oxitónicos, por tanto, no sólo señala el creciente control que los poetas castellanos llegaron a ejercitar sobre la lengua vernácula en su aproximación a los modelos italianos, sino que ilustra la aceptación de la poesía castellana al mismo nivel que la italiana.

De hecho, es Fernando de Herrera quien a fines del siglo dieciséis defiende con más ahínco el castellano, considerándolo superior a la mayoría de las demás lenguas:

\begin{abstract}
Yo respeto con grandísima veneración los escritos y la lengua de los hombres sabios de lialia . . . y al contrario cúlpo el descuido de los nuestros y la poca afeccion, que tienen a honrar la suya; pero . . habiendo considerado con mucha atencion ambas Ienguas, hállo la nuestra tan grande y llena y capaz de todo omamento, que compelido de su majestad y espíritu, vengo a afinnar, que ninguna de las vulgares la excede, y muy pocas pueden pedille igualdad ${ }^{29}$.
\end{abstract}

La versión italianizante que elabora Hozes demuestra además su comprensión del doble papel contradictorio que juega el traductor humanista,

\footnotetext{
${ }^{29}$ Carcilaso de la Vega y sus comentaristas, edición por Antonio GALEGO MOREL, Granada, Universidad de Granada, 1966, pp. 287-288. Herrera alaba el castellano a costa del italiano: "Porque la toscana es muy florida, abundosa, blanda y compuesta; pero libre, lasciva, desmayada, y demasiadamente entemecida y muclle y llena de afectación" (288). Así, refleja la valorización de fines del siglo que se le daba al castellano de lengua "viril" en oposición a las características negativas femeninis que se atribuian a la lengua y poesia italianas. Véase Paul Julian SMath, Barthes, Góngora, and Non-Sense, en "PMLA", I (1986), pp. 92-34.
} 
quien debe ser a la vez fidus e interpres. Al rechazar el reiterativo y abstracto lenguaje cancioneril, Hozes se halla libre, paradojicamente, de restaurar las palabras del texto de Petrarca, ofreciendo al mismo tiempo lo que Norton llama una "cifra alternante" que induce en el lector la ilusion de la plenitud del original (NorToN, 1984, 110). En efecto, la traduccion de Hozes de los Trionfi imparte el sentido original en el mismo número de versos del original. Aunque retiene vestigios del gusto por lo abstracto típico de la poesía cancioneril, como en su selección de mal para traducir los sospiri petrarcanos, la versión de Hozes alcanza un nivel de musicalidad y armonía a través del uso efectivo del lenguaje, de la aliteración, y de cadencia ritmica ajeno al estilo cancioneril de los primeros traductores.

De ahr que la traducción de Hozes apunte hacia el texto original mientras que recupera para el lector el sentido original en un lenguaje diferente, pero igualmente válido. Ası, aunque las traducciones de los Trionfi hechas por Obregon y Gomez presagian el cambio del estilo cancioneril medieval a la poesfa lírica renacentista, es únicamente por medio de la apropiación de la Ifrica petrarcana, lograda por la simultánea independencia y fidelidad de sus traducciones, que el castellano alcanza una posición equivalente a la del italiano. La labor de la traducción en el Renacimiento, pues, significa una nueva corriente ideológica en la poesla lírica española; como esfuerzo literario intimamente relacionado con la imitación de los modelos clásicos e italianos pero significativamente diferenciado de la misma, la traducción asegura la primicia de la lengua castellana al reconocer su deuda con su fuente básica italiana a la vez que proclama su autonomfa.

\section{RÉSUMÉ}

Les traductions des Trionfi de Pérarque au castillan faites au XVIe sidcle offrent un moyen d'evaluer l'évolution des attitudes envers la poétique pétrarquiste, la traduction et la langue vernaculaire. Malgré leur style chansonnière, les prémieres traductions des Trionfi par Antonio de Obregón en 1512 et du Trionfo d'amore par Alvar Gómez confirment la receptivité de la culture espagnòle au développement de la poétique espagnole de la Renaissance et cependant démontrent les difficultés de la traduction ad sensum dans une forme poctique differente.

Basée sur le double propos, apparemment contradictoire, du traducteur humaniste comme fidus et inserpres faite en 1554 par Hernando de Hozes en schéma italianizant de la terza rima s'approprie avec succes les rimes de Pérarque en trasmettant le sense de l'original tout en affimant l'autonomie et primauté du vernaculaire castillan. 


\begin{abstract}
SUMMARY
The sixtcenth century translations of Putrarch's Trionfi into Castilian offer a means of gauging the changing allitudes toward Petrarchist poctics, translation and the vernacular languagec Desplte their cancionero style, the first translations of the Trionfi by Antonio de Ohregrin in 1.512 and of the Trienfer d'annere hy Alvar Grimc\% confirm the receptivity of Spanish cullure (1) the development of Spanish Renaissance prectics, yet demonstrate the diflicullics of translating ced sensuen into a different poctic form. Based on the apparently contradiclory douhle purposse of the humanist translator as fulus and interpres, Hernando de Hores's 1554 translation in Italianale terza riona rhyme scheme sucecessfully appropriates the Pitrarchan lyric, conveying the scense of the original while prociaiming the autonomy amb primacy of the Castilian vernacular.
\end{abstract}

